\title{
Methodological caveats in the environmental modelling and projections of climate niche for ticks, with examples for Ixodes ricinus (ixodidae)
}

\author{
A Estrada-Peña
}

\author{
From The 1st Conference on Neglected Vectors and Vector-Borne Diseases (EurNegVec): with Management \\ Committee and Working Group Meetings of the COST Action TD1303 \\ Cluj-Napoca, Romania. 8-11 April 2014
}

There is a growing interest in inferring the associations of health-threatening arthropods to capture the climate niche to which they associate, projecting such inference on a territory. This is intended to predict the range of distribution of the tick and to understand their responses to climate scenarios, using the so-called correlative models. However, some methodological gaps might prevent to obtain an adequate background against which test hypotheses. We explore, describe and illustrate these procedural inaccuracies with examples focused on the tick Ixodes ricinus, and how these may affect the modelling outcomes. We aim to provide a background of rules against which develop reliable models for these parasites. The use of partial sets of occurrences of the tick might produce unreliable associations with climate because the algorithms cannot capture the complete niche to which the tick is associated. Reliability measures of the model cannot detect these inaccuracies, and undesirable estimations of the niche will prevail in the chain of further calculations. The use of inadequate environmental variables (covariates) may lead to inflation of the results of the model through two statistical processes, called autocorrelation and colinearity. The high colinearity existing in climate products derived from interpolation of climate recording stations is demonstrated, and it is explicitly advised the training of climate models with satellite-derived information of climate, of which colinearity of the time series has been removed through a harmonic regression. The high uncertainty if inference on the climate niche is applied into different time slices,

Correspondence: aestrada@unizar.es

Faculty of Veterinary Medicine. Zaragoza, Spain like projected climate scenarios is also pointed in the results.

Published: 1 April 2014

doi:10.1186/1756-3305-7-S1-018

Cite this article as: Estrada-Peña: Methodological caveats in the environmental modelling and projections of climate niche for ticks, with examples for Ixodes ricinus (ixodidae). Parasites \& Vectors 2014 7(Suppl 1):018.
Submit your next manuscript to BioMed Central and take full advantage of:

- Convenient online submission

- Thorough peer review

- No space constraints or color figure charges

- Immediate publication on acceptance

- Inclusion in PubMed, CAS, Scopus and Google Scholar

- Research which is freely available for redistribution
() Biomed Central 